\title{
In Vitro Study of Antibacterial Activity of Mangle negro Extracts Against Selected Pathogens From Enterobacteriaceae and Bacillaceae Families
}

\author{
Behrooz Alizadeh-Behbahani, ${ }^{1}$ and Farideh Tabatabaei-Yazdi ${ }^{1, *}$ \\ ${ }^{1}$ Department of Food Sciences and Technology, Faculty of Agriculture, Ferdowsi University of Mashhad, Mashhad, IR Iran \\ ${ }^{*}$ Corresponding author: Farideh Tabatabaei-Yazdi, Department of Food Sciences and Technology, Faculty of Agriculture, Ferdowsi University of Mashhad, Mashhad, IR Iran. \\ E-mail: tabatabai@um.ac.ir
}

Received 2014 July 18 ; Accepted 2014 September 30.

\begin{abstract}
Background: In this study, the antibacterial activity of Mangle negro extract against selected pathogens from Enterobacteriaceae and Bacillaceae was evaluated.

Objectives: The antibacterial activity of M. negro ethanolic and aqueous extracts were evaluated, through disk agar diffusion method, extract on medium surface method and microdilution method.

Materials and Methods: This experimental study after collection and preparation of aqueous and ethanolic extracts of M. negro, their effects against human pathogen microorganism were determined.

Results: The ethanolic and aqueous extracts inhibited the growth of all the organisms tested. The minimum inhibitory concentration (MIC) of the extracts ranged between $4 \mathrm{mg} / \mathrm{mL}$ and $64 \mathrm{mg} / \mathrm{mL}$.

Conclusions: The study demonstrated that the ethanolic leaf extract of $M$. negro hold an excellent potential as an antibacterial agent.
\end{abstract}

Keywords: Bacillaceae, Enterobacteriaceae, Mangle negro

\section{Background}

Bacterial pathogens have evolved multiple defense mechanisms against antimicrobial agents and resistance to old and newly produced drugs [1].

Recently, the use of drugs and dietary complements, extracted from plants, has been accelerated [2]. In fact, according to the world health organization (WHO), almost $25 \%$ of modern drugs used in the United States have been extracted from plants [3].

The Mangle negro is a species of flowering plants in the acanthus family, Acanthaceae. M. negro is a subtropical wooden shrub that grows in salt lagoon. M. negro is very hard, adapted to harsh environments where water and salinity levels oscillate [4]. Leaves are 1 to 5 inches long, elliptical, contrary, big, leathern, dark green, glabrous (smooth) above and grayish with a tight felt-like pubescence beneath. The glands on the underside secrete salt [5]. Infectious diseases are caused by pathogenic microorganisms, such as bacteria, viruses or fungi; the diseases can be spread, directly or indirectly, from one person to another. Zoonotic diseases are infectious diseases of animals that can cause disease when transmitted to humans. Inappropriate use of antibiotics has helped create strains of bacterial disease resistant to treatment with different types of antibiotic medications [1].

In this study, the antibacterial activity of M. negro eth- anolic and aqueous extracts were evaluated, through disk agar diffusion method, extract on medium surface method and microdilution method, against Salmonella typhimurium ATTC 14028, Proteus vulgaris ATTC 8427, Escherichia coli ATTC 25922, Bacillus cereus ATTC 14579 and Bacillus subtilis ATTC 23857 in vitro.

\section{Objectives}

The antibacterial activity of $M$. negro ethanolic and aqueous extracts were evaluated, through disk agar diffusion method, extract on medium surface method and microdilution method.

\section{Materials and Methods}

This experimental study was conducted at industrial microbiology laboratory, department of food sciences and technology, Ferdowsi university of mashhad in 2014. The M. negro was collected from countryside of Bandar-e Mahshahr (Khuzestan province, Iran).

\subsection{Plant Extraction}

For aqueous extraction, $10 \mathrm{~g}$ of air-dried powder was mixed with distilled water. The supernatant was collected. After 6 hours, the supernatant, collected at intervals

Copyright (c) 2015, Zahedan University of Medical Sciences. This is an open-access article distributed under the terms of the Creative Commons Attribution-NonCommercial 4.0 International License (http://creativecommons.org/licenses/by-nc/4.0/) which permits copy and redistribute the material just in noncommercial usages, provided the original work is properly cited. 
of 2 hours was pooled and concentrated to make the final volume one-fourth of the original volume. For solvent extraction, $10 \mathrm{~g}$ of air-dried powder was mixed with $100 \mathrm{~mL}$ of organic solvent (ethanol) in a conical flask, plugged with cotton, and then kept on a rotary shaker at $190-220$ rpm for 24 hours [6].

\subsection{Suspension Preparation}

Fresh cultivated S. typhimurium ATTC 14028, P. vulgaris ATTC 8427, E. coli ATTC 25922, B. cereus ATTC 14579 and B. subtilis ATTC 23857 colonies were suspended in $5 \mathrm{~mL}$ of $0.85 \%$ normal saline (DEFCO laboratories, USA).

\subsection{Antimicrobial Test}

The antimicrobial activities of aqueous and ethanolic extracts were determined by filter paper disc and spreading of the extract on medium surface methods as described by Nostro et al.[7].

\subsection{Minimum Inhibitory Concentration (MIC)}

Briefly, serial doubling dilutions of the extract were prepared in a 96-well micro titer plate ranged 264, 128, 64, 32, 16,4 and $2 \mathrm{mg} / \mathrm{mL}$. To each well, $10 \mu \mathrm{L}$ of indicator solution and $10 \mu \mathrm{L}$ of Mueller Hinton broth (DEFCO laboratories, USA) were added. Finally, $10 \mu \mathrm{L}$ of bacterial suspension $1.5 \times 108 \mathrm{CFU} / \mathrm{mL}$ (equivalent to $0.5 \mathrm{McF}$ arland standards) was added to each well. The plates were wrapped loosely with cling film to ensure that the bacteria did not get dehydrated. The plates were prepared in triplicates and then they were placed in an incubator at $37^{\circ} \mathrm{C}$ for $18-24$ hours. The color change was then assessed visually and the lowest concentration at which the color change occurred was taken as the MIC value [8].

\subsection{Minimum Lethal Concentration (MLC)}

The MLC was determined through a series of steps, undertaken after a MIC test has been completed [9].

The employed software was SPSS-18 (USA, II, Chicago, SPSS Inc).Differences at $\mathrm{P}<0.05$ were considered to be significant.

\section{Results}

Antimicrobial effects of ethanolic and aqueous extracts of M. negro, by the agar diffusion method are presented in Table 1. The zone of inhibition in the ethanolic extract varied from $8.5 \mathrm{~mm}$ for S. typhimurium to $24 \mathrm{~mm}$ for B. subtilis and from $7 \mathrm{~mm}$ for S. typhimurium to $19 \mathrm{~mm}$ for B. subtilis in the aqueous extract. It could be seen the both ethanolic and aqueous extracts inhibited the growth of all the test organisms. The MIC and MLC results of ethanolic and aqueous extracts of $M$. negro are presented in Table 2. The MIC of ethanolic extract of M. negro for S. typhimurium, $P$. vulgaris, E. coli, B. cereus and B. subtilis were 32, 8, 16, 4 and $4 \mathrm{mg} / \mathrm{mL}$, respectively. The MIC of the aqueous extract of M. negro for S. typhimurium, P. vulgaris, E. coli, B. cereus and B. subtilis were $64,16,32,8$ and $8 \mathrm{mg} / \mathrm{mL}$, respectively. The MLC of ethanolic extract of M. negro for S. typhimurium, $P$. vulgaris, E. coli, B. cereus and B. subtilis were 64,16,32, 8 and $4 \mathrm{mg} / \mathrm{mL}$, respectively. And the MLC of aqueous extract of M. negro for S. typhimurium, P. vulgaris, E. coli, B. cereus and B. subtilis were $128,32,64,16$ and $8 \mathrm{mg} / \mathrm{mL}$, respectively.

\begin{tabular}{|c|c|c|c|c|}
\hline \multirow[t]{2}{*}{ Type of Extract (Microorganisms) } & \multicolumn{4}{|c|}{ The Concentration of Mangle negro Extracts, mg/mL } \\
\hline & 10 & 20 & 30 & 40 \\
\hline \multicolumn{5}{|l|}{ Aqueous } \\
\hline S. typhimurium & $7.0 \pm 0.50$ & $9.2 \pm 0.57$ & $13.90 \pm 0.50$ & $16.40 \pm 0.28$ \\
\hline P.vulgaris & $8.3 \pm 0.50$ & $11.4 \pm 0.54$ & $14.80 \pm 0.54$ & $17.00 \pm 0.28$ \\
\hline E. coli & $8.0 \pm 0.50$ & $10.2 \pm 0.58$ & $14.10 \pm 0.28$ & $16.70 \pm 0.50$ \\
\hline B. cereus & $9.0 \pm 0.58$ & $12.4 \pm 0.58$ & $15.40 \pm 0.28$ & $18.00 \pm 0.50$ \\
\hline B. subtilis & $10.0 \pm 0.54$ & $13.6 \pm 0.58$ & $16.80 \pm 0.28$ & $19.00 \pm 0.54$ \\
\hline \multicolumn{5}{|l|}{ Ethanolic } \\
\hline S. typhimurium & $8.5 \pm 0.58$ & $11.0 \pm 0.57$ & $15.50 \pm 0.55$ & $19.30 \pm 0.28$ \\
\hline P.vulgaris & $9.6 \pm 0.58$ & $12.3 \pm 0.57$ & $16.40 \pm 0.55$ & $20.10 \pm 0.28$ \\
\hline E. coli & $9.0 \pm 0.54$ & $12.0 \pm 0.58$ & $16.20 \pm 0.50$ & $19.90 \pm 0.58$ \\
\hline B.cereus & $10.7 \pm 0.58$ & $14.3 \pm 0.50$ & $17.50 \pm 0.28$ & $21.90 \pm 0.57$ \\
\hline B. subtilis & $12.0 \pm 0.58$ & $15.1 \pm 0.50$ & $19.90 \pm 0.28$ & $24.00 \pm 0.58$ \\
\hline
\end{tabular}

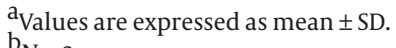

$\mathrm{b}_{\mathrm{N}}=3$.
} 
Table 2. Minimum Inhibitory Concentration (MIC) and Minimum Lethal Concentration (MLC) of Aqueous and Ethanolic Extract of Mangle negro on Salmonella typhimurium, Proteus vulgaris, Escherichia coli, Bacillus cereus and Bacillus subtilis ${ }^{\mathrm{a}}$

\begin{tabular}{lcccc}
\hline Type of Extract (Bacteria Species) & MIC, $\mathbf{m g} / \mathbf{m L}$ & MLC, $\mathbf{m g} / \mathbf{m L}$ & Negative & Positive \\
\hline Aqueous & & & & + \\
\hline S. typhimurium & 64 & 128 & - & + \\
\hline P. vulgaris & 16 & 32 & - & + \\
\hline E. coli & 32 & 64 & - & + \\
\hline B. cereus & 8 & 16 & - & + \\
\hline B. subtilis & 8 & 8 & & + \\
Ethanolic & & & & + \\
\hline S. typhimurium & 32 & 64 & - & + \\
\hline P. vulgaris & 8 & 16 & - & + \\
\hline E. coli & 16 & 32 & - & + \\
\hline B. cereus & 4 & 8 & - & + \\
\hline B. subtilis & 4 & 4 & \\
\hline
\end{tabular}

Abbreviations: +,grow; -, not grow.

$\mathrm{a}_{\mathrm{N}}=3$.

\section{Discussion}

Results obtained from the present study revealed the possess potential antibacterial activity of the two tested extracts against S. typhimurium, P. vulgaris, E. coli, B. cereus and $B$. subtilis. The highest antibacterial activity of $24 \mathrm{~mm}$ was in B.subtilis while the least activity was recorded in S. typhimurium measured $19.30 \mathrm{~mm}$. Tested by the disc diffusion method, the aqueous leaf extracts of $M$. negro showed significant activity against S. typhimurium, P. vulgaris and E. coli around $16.5 \mathrm{~mm}$.

On the basis of the above results, it showed that ethanolic extract of $M$. negro exhibited a greater inhibition compared with aqueous extract. Owolabi and Omogbai reported that most of the antimicrobial active compounds were soluble in a polar solvent like ethanol instead of water [10]. This result is comparable to the study by Nwinyi et al. using ethanolic extract of Ocimum gratissimum that showed effective antibacterial activity on E. coli and Staphylococcus aureus [11]. Kareem et al. studied the antimicrobial effect of ethanolic, aqueous and chloroform extracts of leaf and latex of Calotropis procera on 6 bacteria, 4 fungi and yeast, using agar well diffusion and paper disk methods. The results revealed that the ethanolic was the best extraction solvent for antimicrobial properties of leaf and latex of $C$. procera, followed in order by chloroform and aqueous extracts [12].

The minimum inhibitory concentration values of the plant extracts against the test organisms showed that the bacteria varied widely in the degree of their susceptibility to antibacterial agents. This agrees with the report that antimicrobial agents with low activity against an organism have high MIC while a highly antimicrobial agent has a low MIC [13]. The results indicated that the MLC of the extracts were higher than the MIC. This observation, therefore, suggests that the antimicrobial substances contained in the extracts were fungistatic at lower concentrations while becoming fungicidal at higher concentrations of the extracts. Similar observations have been reported by Yazdi et al. [14]. Mann et al. investigated the antibacterial effects of ethyl acetate, chloroform, ethanolic, methanolic and aqueous root extracts of Anogeissus leiocarpus and Terminalia avicennioidesin vitro for antifungal activities against Aspergillus fumigatus, Aspergillus niger and Penicillium species. They reported that ethanolic extracts of the two plant roots were more effective than the methanolic, chloroform or aqueous extracts against all the test fungi pathogens [13]. In another study, Ekpo and Etim reported that ethanolic and aqueous extracts of Sida acuta were effective against both gram positive (Staphylococcus aureus, B. subtilis) and Gram negative bacteria (Pseudomonas aeruginosa, E. coli) and the antibacterial effect was greater against gram positive bacteria than against gram negative bacteria, showing similar results to those of this study [15]. It was also reported by El-Mahmood et al. [16]. The antibacterial screening of the aqueous and ethanolic extracts of the various plant materials were carried out against pathogenic bacteria including $P$. aeruginosa, Klebsiealla pneumonia, E. coli, S. aureus and Shigella dysenteriae. Ethanolic extracts were more potentthan aqueous extracts and the activity intensity was concentration dependent. The gram positive bacteria were more sensitive to the ethanolic extracts of both plants [16].

The results seem to legitimize the continued use of the extracts in the order of microbial infections. The inhibition of growth of the test organisms, that are known to cause nosocomial infections and displaying multidrug resistant to most antibiotics and non-antibiotic antimi- 
crobial agents, legitimize the continued application of these plants in public and traditional medical practice. Studies should therefore be done in order to know the active phytochemical constituent of the extracts and appraise their effectiveness in vitro so that they can be combined and joinery production begins in serious.

\section{Acknowledgments}

The authors wish to express their profound gratitude and thank sincerely to research's deputy of Ferdowsi university of Mashhad for providing the cost of this project with code 64113060 . The authors wish to express their profound gratitude to Ms. Afsharian who helped about experiments.

\section{Footnotes}

Authors' Contribution:All authors had equal role in design, work, statistical analysis and manuscript writing. Conflict of Interest:The authors declare no conflict of interest.

Funding/Support:Ferdowsi university of Mashhad.

\section{References}

1. Parekh J, Chanda S. In vitro screening of antibacterial activity of aqueous and alcoholic extracts of various Indian plant species against selected pathogens from Enterobacteriaceae. Afr J Microbiol Res. 2007;1(6):92-9.

2. Sharma A, Verma R, Ramteke P. Antibacterial activity of some medicinal plants used by tribals against UTI causing pathogens. World Appl Sci J. 2009;7(3):332-9.

3. Chanda S, Nair R. Activity of some medicinal plants against certain pathogenic bacterial strains. Indian J Pharmacol. 2006;38(2):142.

4. Sobrado MA, Greaves ED. Leaf secretion composition of the mangrove species Avicennia germinans (L.) in relation to salinity: a case study by using total-reflection X-ray fluorescence analysis. Plant Science. 2000;159(1):1-5. [PubMed:11011087]

5. Suarez N, Medina E. Salinity effects on leaf ion composition and salt secretion rate in Avicennia germinans (L.) L.BrazJ Plant Physiol. 2008;20(2): 131-40.

6. Owolabi OJ, Omogbai EK, Obasuyi O. Antifungal and antibacterial activities of the ethanolic and aqueous extract of Kigelia africana (Bignoniaceae) stem bark. Afr J Biotechnol. 2007;6(14):1677-80.

7. Nostro A, Germano MP, D'Angelo V, Marino A, Cannatelli MA. Extraction methods and bioautography for evaluation of medicinal plant antimicrobial activity. Lett Appl Microbiol. 2000;30(5):379-84. [PubMed: 10792667]

8. Khalil R, Li Z. Antimicrobial activity of essential oil of Salvia officinalis L. collected in Syria. Afr. JBiotechnol. 2013;10(42):8397-402.

9. Elgayyar M, Draughon FA, Golden DA, Mount JR. Antimicrobial activity of essential oils from plants against selected pathogenic and saprophytic microorganisms. J Food Prot. 2001;64(7):1019-24. [PubMed: 11456186]

10. Owolabi OJ, Omogbai EK. Analgesic and anti-inflammatory activities of the ethanolic stem bark extract of Kigelia africana (Bignoniaceae). Afr J Biotechnol. 2007;6(5):582-5.

11. Nwinyi $\mathrm{O}$, Chinedu S, Ajani O. Antibacterial effects of extracts of Ocimum gratissimum and piper guineense on Escherichia coli and Staphylococcus aureus. Afr J Biotechnol. 2009;3(1):022-5.

12. Kareem S, Akpan I, Ojo O. Antimicrobial activities of Calotropis procera on selected pathogenic microorganisms. African journal of biomedical research. 2008;11(1): 105-10.

13. Mann A, Banso A, Clifford LC. An antifungal property of crude plant extracts from Anogeissus leiocarpus and Terminalia avicennioides. Tanzan J Health Res. 2008;10(1):34-8. [PubMed:18680963]

14. Yazdi FT, Behbahani BA, Mortazavi A. Investigating the Minimum Inhibitory Concentration (MIC) and Minimum Bactericidal Concentration (MBC) of the Lavandula stoechas L. and Rosmarinus officinalis L. extracts on pathogen bacterias "in vitro". J Paramed Sci. 2014;5(2):91-101.

15. Ekpo M, Etim P. Antimicrobial activity of ethanolic and aqueous extracts of Sida acuta on microorganisms from skin infections. $J$ Med Plants Res. 2009;3(9):621-4.

16. El-Mahmood A, Doughari J, Chanji F. In vitro antibacterial activi ties of crude extracts of Nauclea latifolia and Daniella oliveri. Sci Res Essay. 2008;3(3):102-5. 